\title{
Sports Innovation: New models and future potential
}

\author{
Dr Ashley Hall, Innovation Design Engineering, Royal College of Art
}

Over the past nine years the Innovation Design Engineering masters programme at the Royal College of Art \& Imperial College London has developed the GoGlobal project; a series of cross-cultural educational collaborations with a diverse range of partners in China, Thailand, Ghana, India, Korea and Japan. Over the past nine years we have developed a diverse range of themes ranging of themes that have varied from product urbanisation to post-consumerism, massclusivity ${ }^{1}$, rural urban migration and the future of food. This year in our search for new challenges and innovation spaces we have developed a partnership with the University of Technology in Sydney to bring together a group of 70+ students for an intensive one month project involving the designing, making, testing and proving of sporting innovations in a range of scales and contexts: from body equipment to stadiums, and interventions operating at the scale of the individual to a major infrastructural investments in the city.

So why Australia might you ask? We were drawn to Australia as a country which more than any other has defined its international profile on sporting excellence. With a modest population (22 million people) it has consistently outperformed the rest of the world in a wide variety of sports from track and field to cycling, paralympics, cricket, rugby, sailing and many others. In parallel to this high level of sporting success, Australia has redefined itself culturally as the leisure sporting continent. More than anywhere else it seems, Australians manage to integrate sporting activity into their daily lives and routines.

\section{ULTIMATE ARENA}

Sports are arguably the ultimate arena for competitive human endeavours. Advances in materials and technologies continue to push the human-machine in scenarios where we celebrate cutting edge combinations of technology and human performance attributes. It's our ultimate physical enhancement and it's no wonder that we seek to push the boundaries in all the sports innovation categories where political, ideological, cultural and commercial motivations become publically focussed.

Innovation defines itself by breaking the rules, operating above, underneath, beyond, bending, twisting and ignoring the 'rules of the game' and the sporting environment is no exception. With so much at stake and with fixed rules set by governing bodies, a whole ecology of activities have evolved that seek to gain as many minute advantages as possible in order to produce a winning combination. A concept beautifully summarised by UK Director of British Cycling Dave Brailsford's concept of 'The Aggregation of Minor Gains $^{\prime 2}$ where every minute performance gain is achieved through a forensic analysis of every technique, piece of equipment, venue characteristics, competitive psychology etc. The main categories within which this takes place are techniques, the physical body, equipment, chemicals and psychology or gamesmanship.

\footnotetext{
${ }^{1}$ Massclusivity or exclusivity for the masses is a customisation effect of the increasing fragmentation and individualization of markets as described Chris Anderson's 'Long Tail effect' (2006).

2 The 'aggregation of minor gains' has now expanded out of sport into a wide range of applications including teaching http://www.theguardian.com/teacher-network/teacher-blog/2012/nov/22/olympic-legacymarginal-gains-students
} 
Those pushing the rules too hard in sports are called cheats, those who get away with it are celebrated as winners. Some of the famous examples include Dick Fosbury's innovative technique that saw him compete as the only person to jump backwards in the 1968 Mexico Olympics, now everyone jumps backward. Conversely England's controversial bodyline bowling technique developed to offset the great Australian batsman Don Bradman in the 1932-3 Ashes tour has gone down in history as 'not cricket'. Graham Obree broke the one-hour distance cycling record twice in the early nineties on a handmade bicycle using second hand washing machine parts. His riding position and frame design were subsequently banned by the regulatory body. The cycling world has had its fair share of chemical abuses yet reports that ancient Greeks would think nothing of chewing on raw sheep's testicles to improve performance illustrates a longer precedent. Ultimately our regulatory bodies decide what is fair, based on the long-term health of the athlete, a sense of fair play and relatively even competition. However these examples describe public competition, as much innovation happens in the wind tunnel refining a skier or cyclists' aerodynamic position, training regimes and the training equipment that rarely sees the light of day.

As you can see we are drawing an analogy between innovation, and success and cheating in sports. Both break the rules. In the educational environment we often find this with students whom we train to be great innovators, it means breaking the rules and they often can't see the difference between the industrial and the academic institutional boundaries.

\section{FLAVOURS OF SPORT INNOVATION}

This model of innovation is clearly focussed at elite sports, but there are other drivers and other types of innovation focussed at different levels of sporting activities tha operate at the margins. Our diverse project contexts for the Rio Tinto Sports Innovation Challenge (RTSIC) in and around Sydney explored alternative types of innovations away from an elite focus. The following groups of RTSIC Sydney projects begin to identify new innovation models developed by the student group's different approaches to sports innovation.

Sydney's surf lifesavers became the location for three projects that investigated safety on the ocean's edge. Rip-on, Arc and Pellicam looked at three different aspects of surf safety, warning, monitoring and observation and rescue. Rip-on's smart technologies signposted the dangerous ocean rips that can threaten unwary swimmers, while Pellicam offered the high altitude monitoring of swimmers and surfers while Arc is a remotely controlled flying life preserver courtesy of a foam quad-copter that can be flown out to swimmers in distress. Although not directly focussed at a particular sport all three projects identified this as and under investigated context for innovation and show how smart thinking can improve the safety of environments used for sports and leisure. 


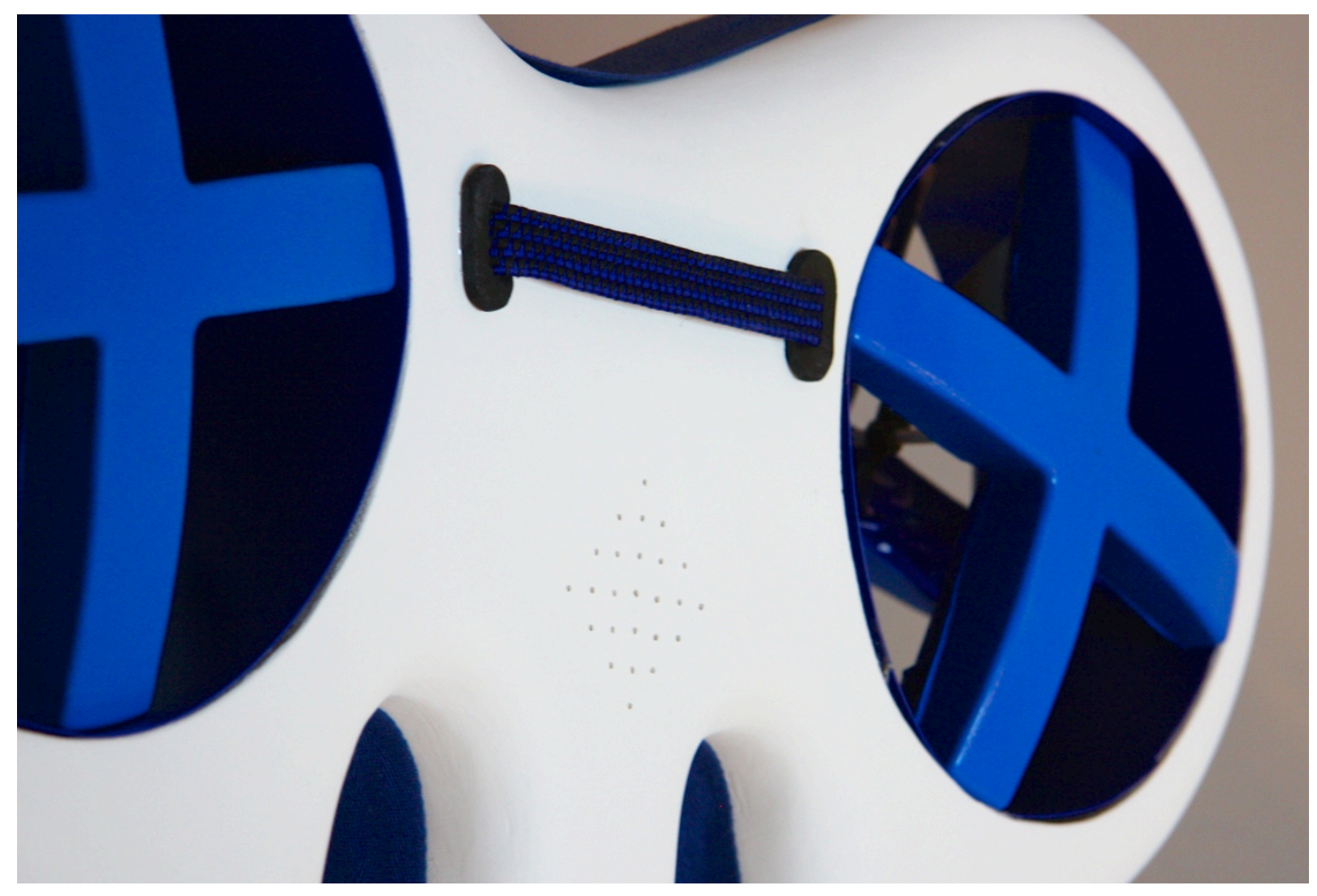

Arc surf lifesaving quadcopter-life preserver: Nell Bennett, Joe Smith, Zack Mitchell, Beatrice Buffa, Shane Chandler.

'Commutersports' is another growing phenomenon, whether its keen cyclists having impromptu races on the their commute home or more organised events like the London Nocturne ${ }^{3}$ folding bike race where competitors in business attire run 20 metres to their bikes, unfold them and race several circuits of the night time city streets. Winners can be best dressed or actually cross the lines first and rules are rather open. RTSIC team Portal pushed into the near future by designing an innovative remote collaborative commuter challenge that allowed runners all over the world to race against each other in real time, producing an 'internet of competition.' This approach uses the rapid growth of digital networks and software to extend the competitive space beyond the local to the global. We have already seen successful globally networked virtual gaming scenarios played by thousands of concurrent gamers. Portal extends this model to multiple physical competitors competing against each other in real time or consecutively through the lightweight projecting display that illustrates competitor's relative position to each other.

\footnotetext{
${ }^{3}$ London Nocturne, http://www.londonnocturne.com/foldingbikerace.php
} 


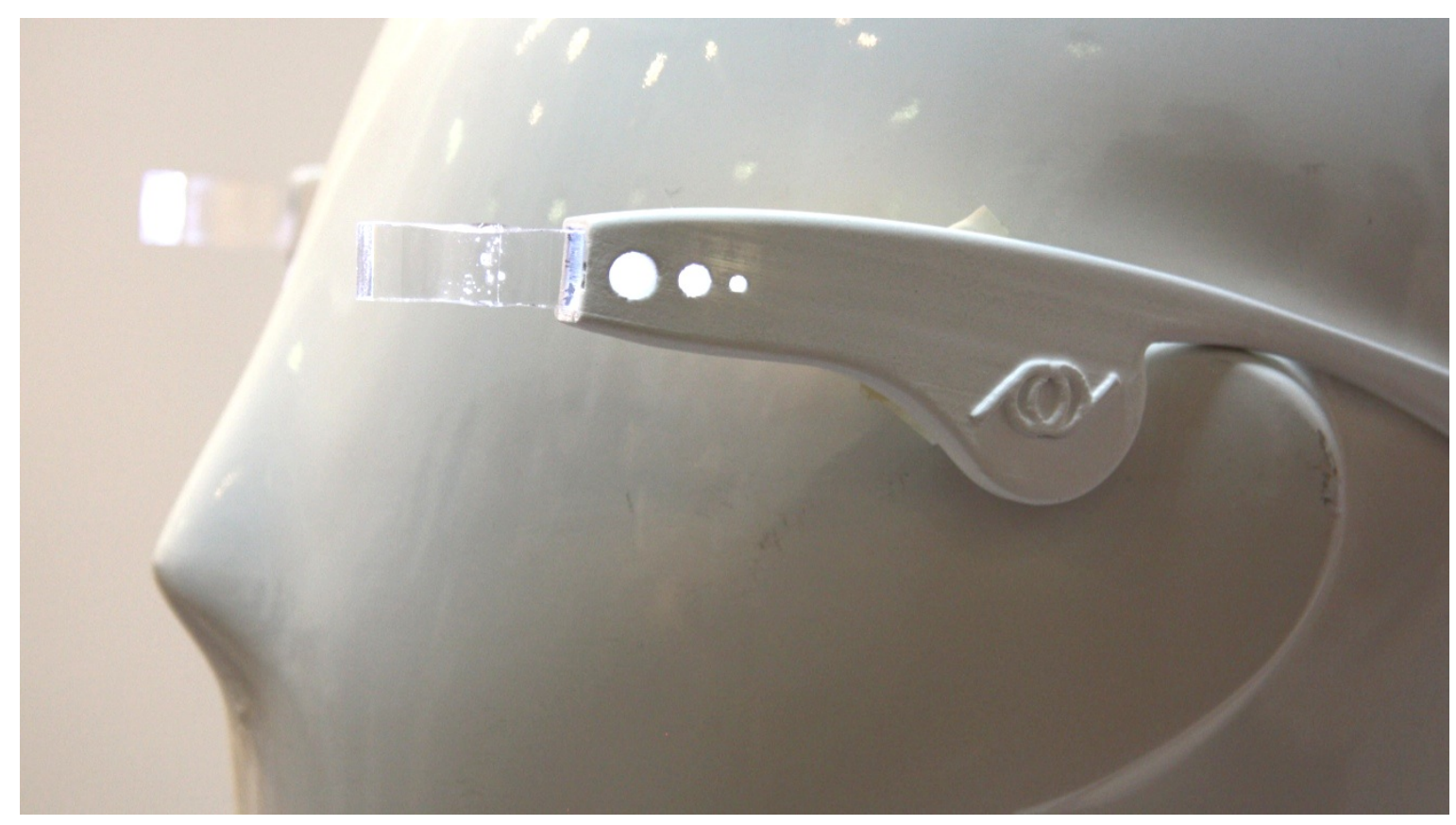

Portal: Carine Colle, Lorraine Fernandes, Timothy Sadler and Peter Spence

Aura, Prescient and Murr-ma innovated in the area of total inclusion by using smart applications of technology to help marginalised people compete in new sporting events. Aura allowed epileptic sufferers to return to cycling by using advanced electroencephalography to provide advanced warnings of oncoming seizures while Prescient employed advances in neuroplasticity to provide a new way to 'see' by linking a forward facing camera to a pad of actuators located on the back of a visually impaired athlete. Murr-ma is an advanced prosthetic designed to facilitate the transfer from surf to beach for lower limb amputees who need to negotiate this difficult transfer barrier. Both of these projects are harnessing biophysiological feedback directly into smart digital systems that can bridge the physical and sensory gaps that allow more and more people to compete at multiple levels from the amateur to the Paralympic. The growing sophistication of digital technology, lowering or component prices and expertise in engineering design and innovation will continue to increase access to include the largest number of athletes. 


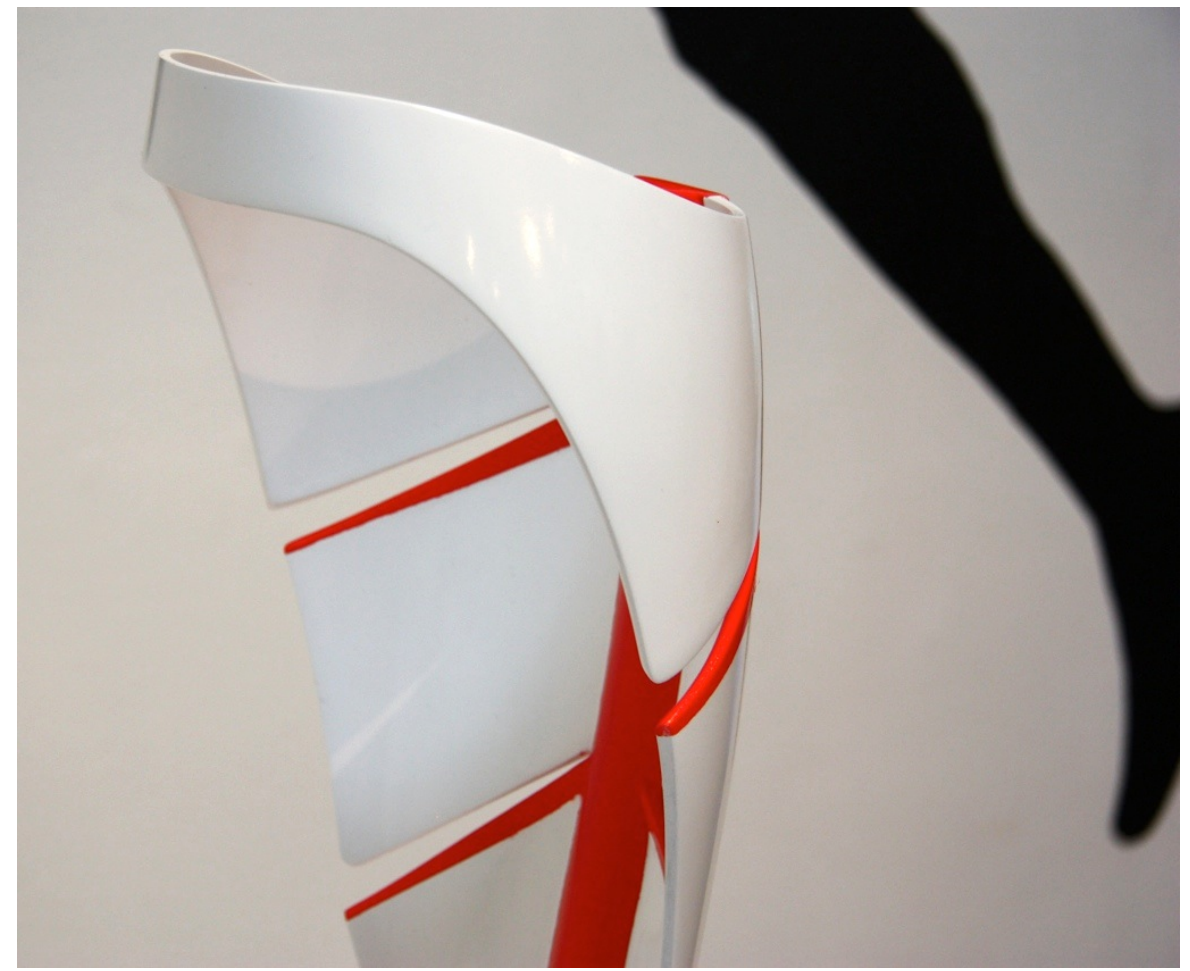

Murr-ma: Julia Johnson, Thomas Essl, Yuki Machida and Damien Rocca

Billion and Urban Racer shifted sports innovation up to the urban and city scale. Billion uses advanced networking and projection technology to place the viewer virtually at an event and allows the user's relative size to be scaled by their reaction to on-pitch action. Urban racer proposes a fully democratic event where able-bodied and Paralympic athletes compete in the same sport on a body hoverboard that runs on a purpose built high level city track. These projects take different strategies to the urban context as Billion leverages digital technology to blur the distinction between being at a game and observing it remotely in a way that allows viewers to influence the stadium dynamic from a distance. This asks interesting questions around some basic sports scenarios like the home and away game advantage and how this could be challenged by the virtual crowd. Hoverboard aimed to give the feeling of an exciting urban sport racing above the city streets and designed the physical interaction so that it can be played by the most inclusive number of competitors possible. Steering on the air hovering platform is achieved by small shifts in body weight. 


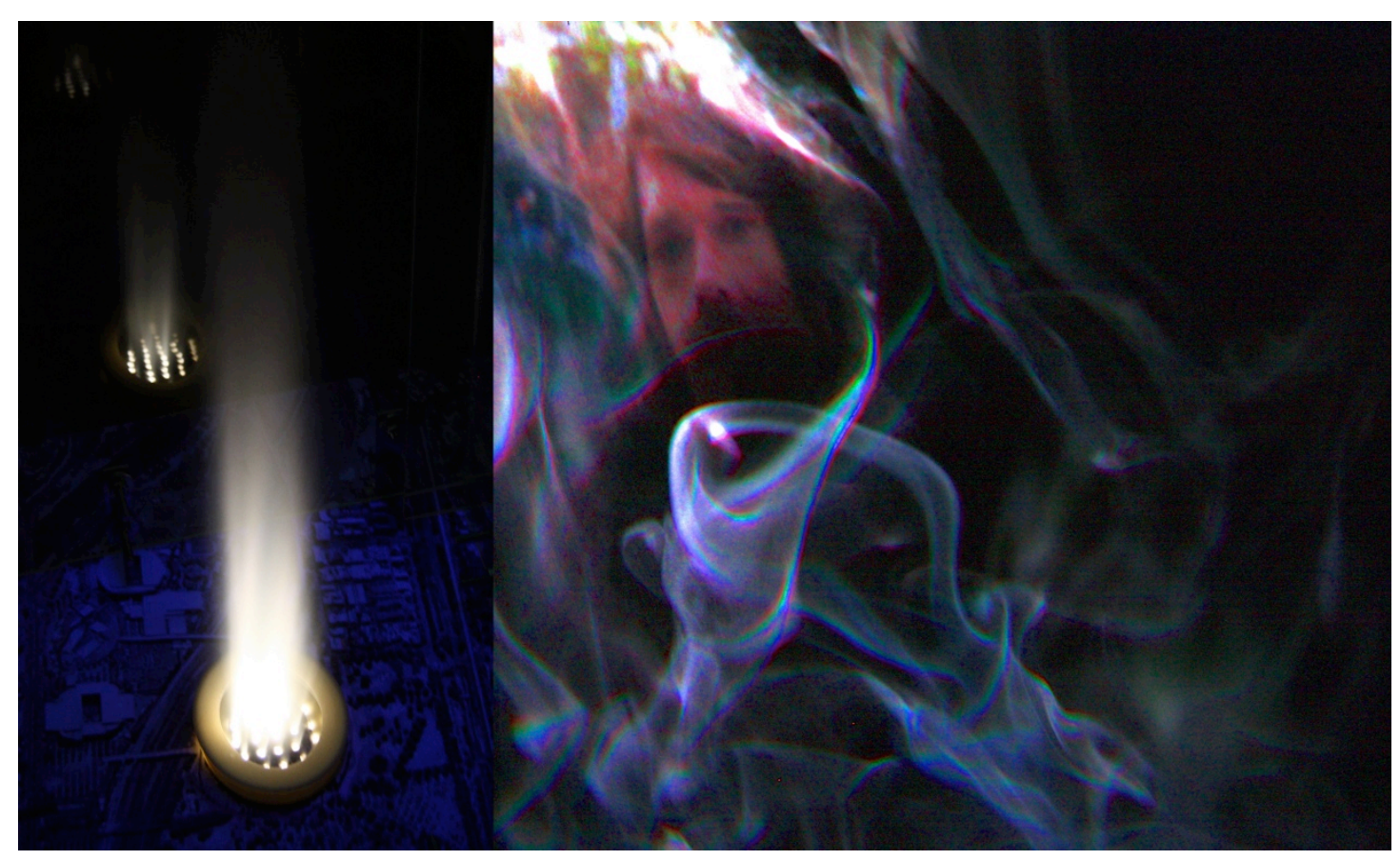

Billion: Jack Hooper, Ashlyn Lee, Yoo Jin Jung, Matthew Lydiatt, Sasha Mijic

Pace and Trajectile looked at sports training and how new digital sensing technologies can enhance virtual training by learning about potential and actual performance and visualising how athletes can bridge the gap. Trajectile investigated smart flooring and how foot positions in a wide variety of sports could be measured and fed back to the athlete so that they could improve techniques and post-examine set pieces in team games. Applications from gymnastics to basketball, javelin, discus and the triple jump are easy to imagine. Pace uses an array of sensors to learn about a cyclist's physical capabilities, then using a head up display it compares visual display elements to trigger the competitive psychology of the athlete to maximise the psychological response to their performance. 


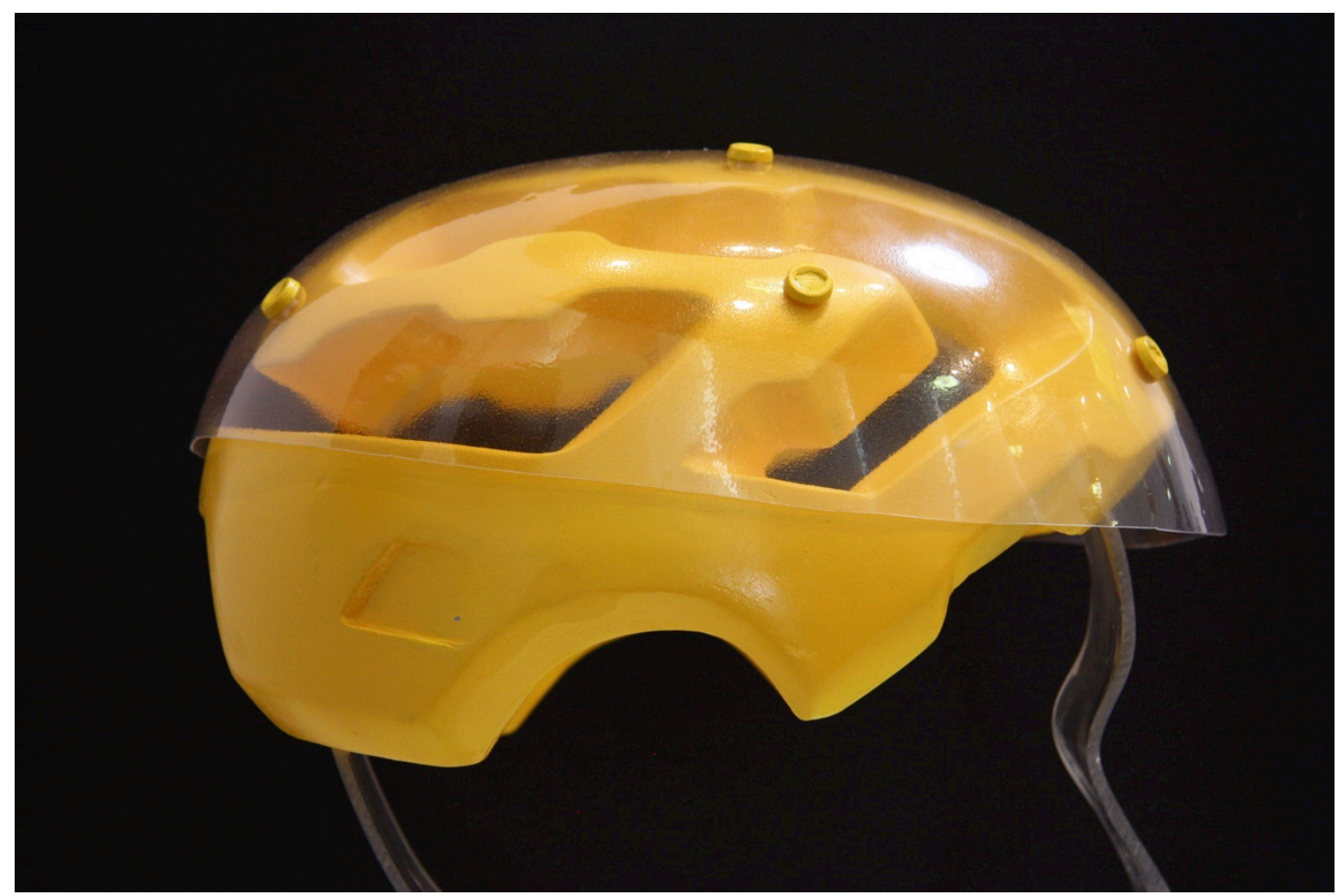

Pace: Paul Stawenov, Thomas Tredinnick, Florian Peuch, Kristopher Stasi

Five different innovation contexts have emerged from the collaborative activities of Innovation Design Engineering, Architects and Industrial design students operating in the form of total inclusion, commuter sports, lifesaving, urban space and enhanced training. The common features running through them are a blend of the competitor, designer and technology driven innovations that reward a synthesis of all the innovation, design and engineering elements.

Breaking the accepted norms of techniques, technology implementation and human enhancement whether it's on the product or the architectural scale means becoming comfortable with risk and design experimentation ${ }^{4}$. Great designers become comfortable with risk and the most gifted become adept at operating as close as possible to the limits of technology, client and marketing acceptability. One of the keys to this success is not to artificially project a solution onto the project in order to be 'comfortable' in its execution, but to trust that ingenuity and creativity in guiding the process will lead to an unpredictable result, delivering the unexpected step-change that we refer to as innovation. The format for this project deliberately set out to provide challenging contexts without inherent problem statements. Problematising design scenarios inevitably leads to simplification through reducing problem statement that eliminate the noise in the creative space thereby reducing the creative possibilities. Our approach when selecting context was to find rich overlays of behaviours, urban space, human performance and technology potential.

Sports innovation is a demanding environment, unforgiving of efforts that ignore the holistic nature of human competition and equipment. The increasing miniaturisation and dematerialisation of our technologies and the emergence of bio-digital technology interfaces will fuel even more sophisticated body enhancements in the long and natural

\footnotetext{
${ }^{4}$ Hall, A., 2011, Experimental Design: Design Experimentation, Design Issues, 27(Number 2, Spring 2011), pp. 17-26.
} 
evolution of the human being from using our first hunting and survival tools through to the new generation of biologically integrated rapid manufactured soft tissue implants.

\section{SPORTS INNOVATION FANTASY}

The RTSIC projects focussed on real world or near future scenarios delivering a package of technology, user focus and vision. There are however other forms of creative envisioning that are being deployed in the sports arena. Contemporary sports products are rarely conceived via a user driven process and very often employ the 'innovation fashions design' model exemplified in technology trainers and bike frames. Fantasy technology and performance for the urban fashionista can be seen in the latest Saloman mountain running shoes that are more likely to be used in central London that the peak district. Ironically cyclists are often willing to pay a cost tariff to shave off a few hundred grams on ultra styled new equipment when their own bodyweight reduction can have a much lager performance gain while costing far less. A literary precursor to this trend was foretold by Philip K. Dick in the Zap gun ${ }^{5}$, a science fiction novel that took an early stab at the ironic application of technology fashion as far back as 1967. Dick highlighted how the appearance of fetishised technology can be a sound marketing recipe when the desire and appearance of consumption begins to outweigh the performance or suitability of the product. Science fiction has a rich seam of sports future gazing ranging from the classics Rollerball and Running Man, to Quidditch or Star Wars pod racers that have all speculated on future sport innovations. The fantasy of competition and technologised aesthetics has become a powerful marketing tool in its own right where 'looking the part' becomes more important that taking part. Such are the ironies of consumption patterns and marketing directions in the twenty first century that illustrate how competitive psychology has transcended into the consumer mindset. These emerge as part of the same trends that see us buying the 'ready for anything' BMW SUV, S-Works full suspension mountain bike and North Face trans Himalayan winter jackets for the benign urban user.

\section{FUTURE}

We should ask ourselves what is missing from this rich band of sports innovation for the $21^{\text {st }}$ century? On the larger scale we seem to be tied to generating small iterative sporting developments or inventing niche extreme sports. The Athenian Olympic sports were largely based on military manoeuvres and combat techniques, so why not take a similar if extreme approach and reconfigure our $21^{\text {st }}$ century sports around $21^{\text {st }}$ century warfare? What would a contemporary Olympics sport look like if it was based on contemporary technology driven military combat? Sport for the consumer is about mass entertainment and its possible to see this evidenced in the myriad rule changes that enhance remote viewing. Yet our viewing media, attention spans and consumption patterns are changing rapidly away from the long game play of traditional team sports.

How will traditional sports keep pace when winning margins continue reducing? Soon the $100 \mathrm{~m}$ record will only be broken every couple of years, then later on every decade when audiences attention will shift to new sporting areas. If we designed new sports with cutting edge technology and physical skills and media friendliness at their core, what could be the result? Most importantly how can we design the longest envelope of

\footnotetext{
${ }^{5}$ Philip K. Dick is well known as the Sci-Fi author of Bladerunner, Minority report and Total Recall. The Zap Gun is one of his lesser-known works published in 1967 and tell the ironic tale of a leading 'weapons fashion designer.'
} 
increased competition so that we don't burn out new sports so they will keep developing ne records, techniques and experiences for competitors and audiences alike.

The five innovation approaches that emerged out of the RTSIC project prove that new forms of design thinking can produce powerful results. The $21^{\text {st }}$ century will undoubtedly be the century of sports as mature audiences, technologies and competitive strategies keep raising the bar and offering challenges to an ever-increasing body of competitors. 